\title{
Totemisme Dalam Teks Ādiparwa
}

Oleh

Ida Bagus Subrahmaniam Saitya

\begin{abstract}
Addiparwa is an early part of the Mahābhārata. Ádiparwa can be considered to consist of 2 (two) separate sections. The first part, presents the framework of the Bhärata epics is the story of the sacrificial ceremony at the behest of King Janamejaya in order to destroy the dragons because King Pariksit who was the father of King Janamejaya was killed by the Taksaka dragon. The second part contains the genealogy of the Pandavas and Koravas, their birth and youth until the marriage of Arjuna to Subhadra. The ardiparwa text also presents another story, the story of Garuda which frees Dewi Winatā's mother from slavery carried out by Dewi Kadrū. The story of the dragons, with the famous dragons, among others Takșaka, Anantabhoga, and Bāsuki. The Mandara mountain range is also presented in the ipdiparwa text, the rotation of the Mandara mountain occurs in the sea of Kșira which then emerges kürmaräja which assists the rotation. This is what gave rise to the concept of totemsime in Hinduism, especially in Adiparwa texts.
\end{abstract}

Keywords: totemsime, Adiparwa text

\section{PENDAHULUAN}

Teks-teks sastra agama yang berbahasa Jawa Kuna yang terdapat di Indonesia, terutama di Bali. Di Bali teks-teks sastra agama tersebut disimpan dalam bentuk lontar-lontar. Di Bali naskah lontar dihargai sebagai "candi pustaka" tempat suci yang dibangun dengan kata-kata terpilih. Esensi dari ratusan lontar yang ada di Bali memiliki tiga tema utama (Agastia, 1987:40). Tiga tema dimaksud adalah jñāna, susila, dan rașa. (1) Tema jñāna, yaitu pengetahuan hakikat dan diwujudkan menjadi lontar tattwa. Isinya didominasi oleh doktrin-doktrin teologi-filosofis. (2) Tema suśila, diwujudkan menjadi lontar sāśana dan nīti. Isi teksnya didominasi oleh ajaran moral dan kepemimpinan. (3) Tema rașa, atau estetikareligius diwujudkan dalam lontar seni dan lontarlontar religius-magis (Suka Yasa dan Sarjana, 2011:2)
Di dalam teks lontar seringkali transformasi ajaran disampaikan dalam bentuk mitos-mitos. Mitologi merupakan kesadaran primitif berupa gambaran-gambaran mengenai dewa-dewi untuk menjelaskan gejala-gejala alam, pandangan moral, estetika, dan memiliki konsep-konsep tentang adikodrati (Bagus, 2000:657). Penganut agama Hindu di Bali masih mempercayai akan keberadaan dan kebenaran mitos, sehingga lontarlontar yang memuat mitologi tetap mendapat perhatian bahkan sangat dikeramatkan. Melalui mitos, masyarakat digiring untuk mulai berpikir tentang inti kesemetaan, dengan media kisahkisah para dewa yang bisa dinikmati dari berbagai kelas pemikiran.

Lontar-lontar di Bali memiliki bentuk dan isi yang beraneka ragam. Hal ini terlihat dalam pengelompokan lontar-lontar di Gedong Kirtya, Singaraja. Pengelompokan tersebut digolongkan menjadi 6 (enam) jenis, yaitu : 
a. Weda, meliputi Weda, Mantra, Kalpasastra.

b. Agama, meliputi Palakerta, Sasana, Niti.

c. Wariga, meliputi Wariga, Tutur, Kanda, Usada.

d. Itihasa, meliputi Parwa, Kakawin, Kidung, Geguritan.

e. Babad, meliputi Pamancangah, Usana, Uwug.

f. Tantri, meliputi Tantri, Satua. (Cika, 2006:2)

Dari pengelompokan di atas cerita Mahābhārata termasuk ke dalam kelompok Itihasa karena Mahābhārata terdiri atas așțadaśaparwa. Cerita Mahābhārata tidak dikenal di India saja, di Indonesia pun cerita tersebut dikenal oleh masyarakat. Mahābhārata yang ada di Indonesia berbahasa Jawa Kuna tidak terlepas dari proyek mangjawaken Byāsamata oleh Raja Dharmawangsa Teguh dari Kerajaan Kediri pada abad IX. Mangjawaken Byāsamata berarti membahasajawakan pikiran-pikiran Maharși Vyāsa, Mahābhārata merupakan salah satu dari proyek tersebut. Menurut Zoetmulder (1994:112-113), parwa yang dapat ditemukan dalam khazanah sastra Jawa Kuna hanya 9 (sembilan) buah, yaitu Ādiparwa, Sabhaparwa, Wirataparwa, Udyogaparwa, Bhismaparwa, Asramawasanaparwa, Mausalaparwa, Prastanikaparwa, dan Swargarohanaparwa.

Dari kedelapan parwa yang berbahasa Jawa Kuna, Ādiparwa merupakan bagian awal dari kitab Mahābhārata. Menurut Zoetmulder (1994:80), Ādiparwa dapat dipandang terdiri atas 2 (dua) bagian tersendiri. Bagian pertama, menyajikan kerangka mengenai epos Bhārata adalah cerita mengenai upacara korban atas perintah Raja Janamejaya dengan tujuan untuk memusnahkan para naga dikarenakan Raja Parikșit yang merupakan ayah dari Raja Janamejaya dibunuh oleh naga Taksaka. Bagian kedua, berisikan silsilah para Pandawa dan Korawa, kelahiran dan masa muda mereka hingga pernikahan Arjuna dengan Subhadrā.

Di samping cerita di atas, di dalam Ādiparwa juga terdapat cerita mengenai Garuda, Garuda anak dari Bhāgawan Kasyapa dan Dewi Winatā. Para naga, dengan naga yang terkenal, yaitu Takșaka, Anantabhoga, dan Bāsuki. Perputaran gunung Mandara, yang pada saat perputaran tersebut muncul kūrmarāja. Hal tersebut dapat menggambarkan konsep totmeisme yang ada di dalam agama Hindu.

\section{PEMBAHASAN}

\subsection{Totemisme}

Totemisme adalah suatu keyakinan akan adanya binatang keramat yang sangat dihormati. Binatang tersebut diyakini memiliki kesaktian, umumnya adalah binatang mitos, juga binatang tertentu di alam ini yang dianggap keramat (Titib, 1996:86).

Dewasa ini, totemisme digunakan untuk menyatakan kepercayaan tentang adanya hubungan yang erat antara satu suku, atau keluarga atau seseorang dengan satu benda atau binatang. Pendapat lain menyatakan bahwa totemisme adalah kepercayaan pada benda atau tumbuhtumbuhan atau hewan-hewan yang disucikan karena dianggap sebagai penjelmaan dari dewa, yang merupakan nenek moyang mereka (Donder, 2009:568).

\subsection{Totemsime dalam Teks Ādiparwa}

Dalam teks Ādiparwa dapat ditafsirkan mengenai konsep totemisme, yaitu mengenai para naga. Para naga dalam teks Ādiparwa merupakan anak dari Bhagawān Kaśyapa dengan Dewi Kadrū, dengan 3 (tiga) naga utama bernama, Anantabhoga, Bāsuki, dan Takșaka. Kelahiran para naga diceritakan dalam teks Ādiparwa berikut ini.

Mangkana ling sang Kadrū. Irikā ta sira wineh antiga sewu, makatêtêsana dlāha. Kunang ling sang Winatā:

Sojar mpungku! Haywākeh paweh rahadyan sanghulun putra ri kami, rwang siki juga! Anghing lwiha ring kaśaktin sangkeng anak sang Kadrū, yatikā paweha ra mpu ri nghulun.

Nāhan ta ling sang Winatā. Wineh ta sira 
hantiga rwang siki. Ya ta pinahayu nira ikang antiga, paweh sang swāmi kinêkêsan ira ring dyun rinakșa nira. Limang atus tahun lawasnya, anêtês ta anak sang Kadrū hantiga sewu. yatikātěmahan nāga, pinakädinya sang Anantabhoga, sang Bāsuki, Takșaka kapwa pada mahāśakti sira kabeh. (Ädiparwa V.25)

Terjemahannya :

Demikian kata sang Kadrū. Pada waktu itu ia lalu diberinya telur seribu butir, yang kelak akan menetas.

Adapun kata sang Winatā: "Ya tuan pendeta, tidak usah banyak anugerahmu kepada saya, dua orang anak sajalah, tetapi hendaknya kesaktiannya lebih daripada kesaktian anak sang Kadrū, itu sajalah anugerahmu kepada saya".

Demikian kata sang Winatā. Ia lalu diberinya dua butir telur. Dijaganya dengan hati-hati telur pemberian suaminya itu, disimpan di dalam jun (tempayan) dan dibelanya.

Setelah lima ratus tahun berlalu, anak sang Kadrū seribu butir telur menetaslah. Semua berwujud naga, sebagai pemukanya sang Anantabhoga, sang Bāsuki, sang Takșaka, semuanya sangat sakti (Zoetmulder, 2006:52-53).

Kutipan teks Ādiparwa di atas, Bhagawān Kaśyapa memberikan 1000 (seribu) butir telur kepada Dewi Kadrū agar ia memiliki anak dan 500 (lima ratus) tahu kemudian menetaslah telur tersebut yang semuanya adalah naga. Ada 3 (tiga) naga yang menjadi pemimpin para naga, yaitu Anantabhoga, Bāsuki, dan Takșaka. Dalam cerita Ādiparwa selanjutnya, naga Anantabhoga dianugerahi oleh Bhațāra Brahmā untuk menahan bumi, hal tersebut diuraikan berikut ini.

Sojar mpungku, tan sangsaya rahadyan sanghulun mangke, ulah nikang nāga ri huwusnyān śināpa de sang ibu glana àśà śoka, ikang nāga anak atuha de sang Kadrū amrih ta yāgawe tapa sira, umārāadhana bhațāra Brahmānugraha ta sira, sumanggā prthiwìtala, tan katêkāna de ning sarwaduhka, "kadi lwirku ta lwiranta". Mangkana ling bhațāra Brahmā irikang nāga, ya ta matang yan adharana prthiwi, sira ta sang Anantabhoga ngaran ira. kunang wwang sānaknya kabeh, makādi sang Bāsuki sira tāhöm umālocita de nikā. Kapwākira-kiramājar $i$ sang Bāsuki, lingnya: (Ādiparwa VII.2)

Terjemahannya :

Baiklah tuanku, janganlah tuanku kuatir. Para naga sesudah dikutuk ibunya menjadi gundahgulana putus asa dan bersedih hati.

Naga yang tua, anak sang Kadrū itu, bertapa memuja kepada batara Brahmā, diberinya pekerjaan, menahan bumi, tidak mengenal susah: "Seperti akulah keadaanmu!" Demikian kata batara Brahmā kepada naga, karenanya lalu menahan bumi, yaitu namanya Anantabhoga.

Adapun sanak-saudaranya dengan dipimpin oleh sanghyangBāsuki, bersidang, meperbincangkan, bagaimana caranya mendapatkan ketentraman. Semua memikirkannya, lalu ada yang berkata kepada sang Bāsuki, katanya: (Zoetmulder, 2006:77)

Oleh karena para naga dikutuk oleh ibunya, maka Anantabhoga memuja Bhațāra Brahmā dan dianugerahi untuk menahan bumi. Mitos 3 (naga) inimenurut Wiana(2009:26-27) adalah penjelmaan dari para dewa karena melihat keadaan makhluk hidup di bumi sangat sengsara, maka Dewa Śiwa mengutus Dewa Brahmā untuk menjadi naga Anantabhoga, Dewa Wișṇu menjadi naga Bāsuki, dan Dewa Íśwara menjadi naga Takșaka. Naga Anantabhoga berada di dalam tanah, kepala dari naga Bāsuki menjadi laut dan ekornya menjadi gunung, sedangkan naga Takșaka yang bersayap terbang memasuki lapisan angkasa.

Dalam teks Śiwāgama disebutkan setelah bumi ini diciptakan oleh Bhațāra Śiwa dan Bhațāri Umā, pada suatu saat terjadi bencana, tumbuhtumbuhan tidak hidup dengan baik, air tidak berkhasiat, serta udara menimbulkan penyakit. Oleh karena itu, Sanghyang Trimūrti turun ke dunia untuk membantu para manusia. Bhațāra Brahmā masuk ke dalam tanah dan berubah menjadi naga Anantabhoga, Bhațāra Wiṣnu terjun ke dalam air berubah wujud menjadi naga Bāsuki, dan Bhațāra Iśwara masuk ke dalam udara berubah menjadi naga Takșaka (Titib, 2003:398). 
Tiga naga tersebut merupakan perwujudan dari Bhațāra Brahmā, Bhațāra Wiṣnu, dan Bhațāra Iśwara yang turun ke dunia untuk membantu umat manusia. Anantabhoga, terdiri dari kata ananta berarti 'tidak habis', dan bhoga berarti 'makanan'. Jadi, naga Anantabhoga berarti makanan yang tidak pernah habis, oleh karena itu maka naga Anantabhoga masuk ke dalam tanah dan memberikan segala makanan yang tidak akan pernah habis kepada makhluk hidup. Bāsuki berarti 'kemakmuran', maka naga Bāsuki masuk ke dalam laut yang memberikan kemakmuran kepada seluruh makhluk hidup di bumi. Naga Takșaka yang masuk ke dalam udara memberikan kehidupan bagi seluruh makhluk hidup.

Perwujudan 3 (tiga) naga tersebut dapat dimaknai secara simbolis sebagai bumi (tanah, air, dan udara) yang digambarkan sebagai induk dari para naga, yaitu Anantabhoga, Bāsuki, dan Takșaka. Para naga tersebut berhasil menipu Dewi Winatā pada saat bertaruh kuda Uccaihśrawa sehingga Dewi Winatā menjadi budak dari Dewi Kadrū, hal ini dapat dimaknai bahwa segala kemakmuran yang diberikan oleh Tuhan apabila tidak dimanfaatkan sebaik mungkin dapat menyebabkan manusia menjadi serakah. Oleh karena harta benda duniawi dapat menipu manusia sehingga terbelenggu oleh ikatan keduniawian.

Mitos para naga tersebut juga diceritakan pada saat pengadukan laut Kșīra, di dalam laut Kșīra terdapat gunung Mandara yang dicabut oleh naga Anantabhoga untuk mengaduk laut Kșīra seperti yang diuraikan berikut ini.

Mangkana ling sang hyang Nārāyana, hinaywan sira dening dewāsurasanggha. Lumāmpah ta sira kabeh mareng Kșīrārnawa. Hana ta Mandara giri ngaranya, gunung ing Śangkadwipa, ikang bhumi makatasik irikang Kșīrārnawawa, ruhurnya, ekā daśasahasrāni, sawêlas iwu yojana.

Adhoh bhümeh sahasrāni, kunang pasirnya sewu yojana. Samangkana krama m lwānya ikang Mandaragiri. Yatika dinawut de sang hyang Anantabhoga, katūt têkeng isinya kabeh tinibākên ing Kșīrārnṇawa, mapakêna pamutêra nikang tasik. Mojar tang dewatā ri sang hyang Samudra:

(Ádiparwa V.30)

Terjemahannya :

Demikian sang hyang Nārāyana disambut oleh golongan dewa dan asura. Mereka lalu pergi ke laut Kșira.

Sebuah gunung, Mandara namanya, gunung di tanah Śangka; tanah yang mepunyai laut Kșīra itu, tinggi gunung itu, ekādaśaśahasrāni, sebelas ribu yojana.

Adhoh bhūmeh sahasrāni, pasirnya seribu yojana. Demikianlah keadaan (ukuran) gunung Mandara. Gunung itu dicabut oleh sang hyang Anantabhoha, terbawa dengan segala isinya, dan dijatuhkan pada laut Kṣīra, akan dipakai sebagai pengebur laut itu.

Lalu berserulah para dewa kepada sang hyang Samudra (Zoetmulder, 2006:55)

Pengadukan laut Kṣīra yang dilakukan oleh para dewa dan para daitya adalah untuk mendapatkan amṛta yang terdapat di dalam gunung Mandara. Dalam hal ini, naga Bāsuki membelit gunung Mandara agar tidak meloncat ke atas dengan ditopang oleh Kūrma di bawahnya. Kūrmarāja yang dimaksudkan adalah avātara dari Bhațāra Wiṣnu, kūrma ini merupakan konsep totemisme dalam Hindu. Mengenai Kūrma dalam pemuteran gunung Mandara dapat dilihat sebagai berikut.

"Tāsyāsih ta kamung hyang Sāgara! haywa kita tan dhārana ri pangaras ning dwipa! Yapwan siddha mijil ikang amrta sangkeng Kșīrārṇawa atyanta paritușta nikang tribhuwana, mwang mahädibyanta, wênang maweh suka ning watêk hyang".

Mangkana ling sang watêk dewatā, manggā ta sang hyang Samudra. Hana ta sang Akūpa ngaranya, Kūrmarāja ratu ning pās, angśa. Bhațāra Wiṣnu kacaritanya ngūni. Sira ta kinon dhumāraṇā ng awak sang hyang Madarādri, pinaka dasar ing bungkah ing parwata, matang yan pingsora. Sang hyang Bāsuki sira pinakatali, amilěti pārśwa nikang parwata, mwang sang hyang Indra manunggang ing agra nira, pinaka panitih 
i ruhur, yatanyan tan mingruhura hidêpnya. (Ädiparwa V.31)

Terjemahannya :

"Kasihanlah kami, hai sang Sagara. Janganlah sampai tidak mengabulkan penyentuhan pulau ini. Jikalau amṛta keluar dari laut Kșīra, alangkah senangnya ketiga benua (dunia); atas keunggulan memberi kegembiraan kepada golongan dewa".

Demikian kata golongan dewa sang hyang Samudra pun memperkenankannyalah.

Ada seekor penyu namanya Akūpa, kūmarāja raja penyu, kabarnya penjelmaan "batara Wiṣnu, dahulu kala. Ia disuruh menahan gunung Mandara sebagai dasar pangkal gunung itu supaya tiada tenggelam. Sang hyang Bāsuki dipergunakan sebagai tali, membelit pada lereng gunung tersebut, dan Sang hyang Indra menunggangi puncaknya sebagai pengendara di atas, supaya tidak melambung ke atas (Zoetmulder, 2006:55-56).

Kutipan di atas, setelah para Dewa mengajukan permintaan kepada Sanghyang Samudra untuk mengaduk laut Kșira dan Sanghyang Samudra menerima permintaan dari para Dewa. Dalam pengadukan laut Kșīra, gunung Mandara yang digunakan sebagai pengebur ditahan oleh Kūrma dan dibelit oleh naga Bāsuki agar keadaan gunung Mandara stabil. Kūrma tiada lain adalah avatāra Wiṣnu yang berwujud kurakura raksasa yang berada di laut Kșîra.

Adapun nama lain dari Kūrma avatāra, antara lain kūrmarāja, badavāgni, akūpāra, ratuning pās, badawa, badawang, badawangnala, yang semuanya diartikan sebagai avatāra Wișṇu dalam wujud penyu atau kura-kura yang menyangga bumi untuk menyelamatkan manusia dari kehancuran (Titib, 2003:405-406).

Konsep totemisme yang lain di samping para naga dan kūrma terdapat di dalam teks Ādiparwa mengenai Sang Garuḍa. Sang Garuḍa merupakan anak dari Bhagawān Kaśyapa dengan Dewi Winatā, dengan kata lain Garuḍa merupakan saudara tiri dari para naga. Diceritakan tentang kelahiran Garuḍa bahwa Dewi Winatā memohon 2 (dua) butir telur saja kepada Bhagawān Kaśyapa namun agar memiliki kesaktian yang lebih dari anak Dewi Kadrū, pada saat Dewi Kadrū sudah memiliki anak sedangkan Dewi Winatā belum menetas telurnya, maka ia memecahkan telurnya dan lahirlah Sang Aruna yang merupakan kakak dari Sang Garuḍa. Hal tersebut diuraikan berikut ini.

Kunang sang Winata tanpanêtês anak nira. Merang ta sira, tumungkul sira, kasoran ta hidêp nira ry awak nira. Sandeha ta manah nira, yan tan dadya ning anak nira. Binêlah ta ng antiga de nira, Pūrwadese tu utpannam tatra putram adrśsyate.

An bêlah tikang antiga, katon tānak nira. Ndān satêngah ry awaknya dadi, ikang $i$ ruhur nikā ya makadi ng muka, pūrṇa ya. Kunang ikang suku tapwan dadi kabeh. Krodha tikang rare, an tinêtês tan māsanya. Ya ta matang yan śināpa sang ibu lingnya: (Ādiparwa V.26)

Terjemahannya

Sedang anak sang Winatā tidak (belum) menetas. Malulah ia menundukkan kepala, pada perasaannya ia mendapat kekalahan. Hatinya kuatir kalau-kalau anaknya tidak akan menetas, karena itu telurnya lalu dipecahnya, Pūrwadese tu utpannam tatra putram adṛśyate.

Ketika telur itu pecah, terlihatlah anaknya baru separuh badannya yang jadi, yaitu bagian atas, terutama mukanya sudah sempurna, tetapi kedua kakinya belum. Anak tadi marah, karena ditetaskan sebelum waktunya, maka dari itu dikutuknya ibunya: (Zoetmulder, 2006:53).

Oleh karena belum waktunya untuk menetas, maka Sang Aruna menjadi marah dan mengutuk ibunya Dewi Winatā, bahwa ibunya akan diperbudak oleh Dewi Kadrū dan hanya adiknya Sang Garuḍa yang dapat menyelamatkan Dewi Winatā. Sang Aruṇa kemudian menjadi kusir Sanghyang Āditya sedangkan Dewi Winatā menjaga dan memelihara telur yang tersisa, seperti yang diuraikan berikut ini.

Nāhan ta ling rare, an śumāpa sang ibu; anak sang Winatā mangkana kramanya, sang 
Aruṇa ngaran ira, matang yan anūruh, tan hana ng pupū têkwan pāda, pinakasārathi de sang hyang Āditya sira. Ya ikang abāng tejanya ring sakata mbesuk. Kunang ikang antiga kari sasiki pinahayu, kinayatnêkên de sang Winatā.

Hênêngakna ng kathā sakarêng, tucapa sang samudramanthana, sangka nikang Uccaihśrawān mijil, ika sang Winatā nimittanyān pinakahulun de sang Kadrū, aparan kramanya nihan: (Ādiparwa V.28)

Terjemahannya :

Demikian kata anak itu mengutuk ibunya, anak sang Winata namanya sang Aruṇa, karena anūruh tiada berpupu, tiada pula berkaki, menjadi sais sang hyang Āditya. Itulah yang bersinar merah pada pagi hari. Adapun telur yang tinggal sebutir itu, dipelihara dan dijaganya dengan hati-hati oleh sang Winatā.

Tiada terkatakan lagi ceritera ini, tersebutlah pengeburan samudra, tempat lahirnya kuda Uccaihśrawā, itulah yang menyebabkan sang Winatā diperbudak oleh sang Kadrū ceriteranya demikian: (Zoetmulder, 2006:54).

Kutukan dari Sang Aruna membuat Dewi Winatā menjaga telur yang tersisa agar setelah Sang Garuda menetas dapat membebaskan dirinya dari perbudakan. Perbudakkan yang dilakukan oleh Dewi Kadrū terhadap Dewi Winatā, karena Dewi Winatā kalah taruhan mengenai warna kuda Uccaihśrawa. Dewi Kadrū menang karena kelicikannya, ia menyuruh anaknya menyemburkan bisa ular agar warna kuda Uccaihśrawā menjadi hitam sehingga Dewi Winatā menjadi kalah. Setelah Sang Garuda lahir, maka ia menggantikan ibunya menjadi budak Dewi Kadrū dan menjaga para naga yang merupakan saudara tirinya, hal tersebut dijelaskan berikut ini.

Nāhan ta ling sang Kadrū, ndatan anggā ikang nāga ri pakon sang ibu, apan tan yogya ng ulah mangkana. Krodha ta sang Kadrū tan pinisinggih sawuwus nira, śināpa nira tānak nira:
"Sarpa satre wartamāne pāwako wah pradhakșyati, atyanta niṣturanta kamung nāga sapinta-kāsihku, tasmād duhka panggihêyu, panganên ing apuy ta ko kāla ning yajña sarpa gawe mahārajā Janamejaya".

Nāhan śāpa sang Kadrū ry anak nireng nāga, karêngö ta panāpa nira de bhațāra Brahmā, inanu moda de nira ng śapatha. Samangkanāta kāla bhagawān Kāśyapa an wineh adyā wișa de bhațāra Brhmā, ngkānê tīra ing Kșīrārnawa. Sinwagatan ta sira de sang ibu, akon tamolahe sang Kadrū. Pira kunang lawas nirān sewaka ri sang Kadrū, tamolah sira, mahyun ta sang Kadrū, mamêngamênga ri tīra ning samudra. Kinon ira ta sang Winatānunggwi ari sira, sang Garuda kinon irānunggweng nāga kabeh, têkeng sūrya mandiala. Kapanasan ta ya sahananya, glana katīṣnan de ni teja sang hyang Āditya. Mawělas ta sang Kadrū tumon ry anak nirān kapanasan. Managstuti ta sireng sang hyang Indra, têka tang megha sakeng daśa saha kilatnya gêrêhnya ghoratara magêtituran. Ya tika manghudanakên, matang yan matis manah nikang nāga wêkasan. Lungha tang nāga tan tunggal paranya; mahas ing sarwadwipa, asing alas piranparanya.

(Ādiparwa VI.6)

Terjemahannya :

Demikian kata sang Kadrū, para naga tidak mau menurut perintah ibunya, karena perbuatan demikian tidaklah pantas. Sang Kadrū marah karena perintahnya tidak dituruti, anaknya lalu dikutuk: Sarpa satre wartamāne pāwako wah pradhakșyati, sangatlah kejammu, hai kamu para naga menentang permintaanku, kelak kamu akan mendapat sengsara, dimakan api pada korban ular yang dilangsungkan oleh maharaja Janamejaya. Demikian kutuk sang Kadrū kepada para naga, anaknya; batara Brahmā mendengar kutuk itu, lalu menjadi saksi atasnya. Pada waktu itulah bagawan Kaśyapa diberi penolak bisa oleh batara Brahmā, mantra penawar waktu itu berada di tepi laut, kșīra. Garuda disambut oleh ibunya, dan ia disuruh tinggal di situ untuk keperluan sang Kadrū. 
Tidak terceritakan berapa lamanya ia menjadi budak, sang Kadrū ingin bercengkerama di tepi samudra, sang Winatā disuruh menjaga adiknya (madu), sedang sang Garuḍa disuruh menjaga para naga. Para naga terus dibawa terbang ke daerah matahari; karenanya mereka kepanasan, bubar merana oleh terik panas matahari. Sang Kadrū pun merasa kasihan melihat anakanaknya kepanasan, lalu ia memuja hyang Indra. Kemudian datanglah awan dari segala arah dengan kilat dan guruhnya, bergelegar dengan suara yang sangat kerasnya. Lalu hujan pun turunlah, karenanya para naga menjadi sejuk. Naga-naga itu pun pergilah ke mana saja, pergi ke segala tempat, segala hutan dimasukinya (Zoetmulder, 2006:62-63).

Pada saat Sang Garuḍa menjadi budak Dewi Kadrū dan menjaga para naga, ia sangat kelelahan dan memohon kepada para naga agar dibebaskan dari perbudakkan. Namun, para naga mengajukan sebuah syarat agar Sang Garuḍa mengambil amrta kemudian diserahkan kepada para naga, setelah itu Dewi Winatā dan Sang Garuḍa terbebas dari perbudakkan. Kemudian, Sang Garuḍa menuju gunung Somaka tempat amṛta berada, amṛta tersebut dijaga oleh para dewa, seperti yang diuraikan sebagai berikut.

\section{Mangkana ling bhagawān Wṛaspati,} kumon $i$ sang dewasangha, rumasekang amrta don ira. Kapwa ta sangrabdha ri pa sangkêpan ikang sañjata, mamariwrtekang Somakagiri, kahanan ikang amrta. Datêng ta sang Garuḍa makapangharêp bāyubajrojwalāndhakara, lêbū mêlêk deny angin-angin $i$ hêlar sang Garuḍ, tātan katon ikà daśa deśa kadi kasaputan hìma rūpanya. glāna ta sang dewatā sawatêk hyang Indra.

(Ädiparwa V.29)

Terjemahannya :

Demikianlah kata bagawan Wṛhaspati, memerintah kepada golongan dewa supaya menjaga amrta. Semua mempersiapkan senjata, menjaga gunung Somaka tempat amṛta.

Sang Garuḍa datanglah didahului oleh angin, kilat dan cahaya yang membuat mata menjadi buta; debu bergumpal-gumpal kena angin sayap sang garuḍa. Semua arah tiada nampak, bagaikan tertutup awan. Para dewa segolongan menjadi gundah-gulana, demikian pula hyang Indra (Zoetmulder, 2006:71).

Kehebatan Sang Garuḍa untuk mengambil amṛta terlihat saat Sang Garuḍa datang didahului dengan angin, kilat, dan cahaya, kesaktian Sang Garuḍa sangatlah hebat. Tidak terelakan pertempuran Sang Garuḍa dengan para dewa, segala senjata para dewa tidak dapat melukai Sang Garuḍa, dan para dewa yang kewalahan menghadapi serangan dari Sang Garuḍa. Melihat kejadian tersebut, Bhațāra Wiṣnu datang menemui Sang Garuḍa, kemudian Sang Garuḍa diminta oleh Bhațāra Wiṣnu untuk diberikan anugerah. Namun Sang Garuḍa menolaknya, karena kesaktian ia melebihi para dewa, hal tersebut dijelaskan berikut ini.

Mangkana ling bhațāra Wiṣnu. Sumahur sang Garuda: "Tan yogya kitānganugrahana kami bhațāra Wiṣnu, apan sor prabhāwanta dengku, ikang amrta ngaranya dentakahatana, kahanan jaramarana. Kunang aku: Ajaraś cama racca syām. Anādhi, tar kênang tuha-pati. Amrtena winā 'py aham, an tan panginum amrta. Mangkana lwirku, tāmalaku ta kitānugrahery aku!'”. (Ādiparwa VI.34)

Terjemahannya:

Demikian kata batara Wiṣnu, menjawab sang Garuḍa, katanya: "Tidak selayaknya engkau menganugerahi aku, batara Wiṣnu, karena kesaktianmu kalah dengan kesaktianku. Karena amrrta itulah engkau tiada mengenai tua dan mati. Tetapi aku: Ajaraścāmaraśca śyām. Anādhi, tidaklah mengenal tua dan mati. Amṛtenawina 'py aham, meskipun tidak minum amṛta, demikianlah keadaanku, mintalah (yang lain) kepadaku supaya kuanugerahi (Zoetmulder, 2006:73-74).

Sang Garuḍa meskipun tidak meminum amṛta, ia dapat hidup abadi dan tidak mengenal tua, berbeda halnya dengan para dewa yang minum amṛta untuk mendapatkan keabadian. Perkataan Sang Garuḍa bahwa ia lebih hebat dari para dewa pun disetujui oleh Bhațāra Wisnu. Oleh karena Sang Garuḍa menolak meminta anugerah dari Bhațāra Wiṣnu, maka Bhațāra Wiṣṇu meminta 
Sang Garuḍa untuk menjadi kendaraan beliau. al tersebut dapat dilihat berikut ini.

Nāhan ling sang Garuḍ, sumahur ta bhațāra Wiṣnu: "Yukti iku ujarta sang Garuda, tan hana salahnya. Pasyasih ta ri kami, tan dadi kitādwawacana, ndak palaku kita wāhanangku, lāwan tulisakna ri dhwajatandāngkwa pakênānta”.

An mangkana ling bhațāra Wiṣnu, mangênangên ta sang Garuda, ndātan anggā sira, anghing mawêdi ring mithyawāda sira. Manggā ta ya wêkasan, matang yan pinakawāhana de bhațāra Wiṣnu. Huwus maprīti kari sang Garuda mwang bhațāra Wiṣnu.

Datêng sang hyang Indra sumêmbah sang Wainateya, apan tan panganini bajra nira. mojar ta sang Garuda. (Ädiparwa VI.35)

\section{Terjemahannya:}

Demikianlah kata sang Garuḍa, batara Wiṣṇu menyahut:

"Sang Garuḍa, katamu itu benar, tiada salahnya sedikit pun. Kasihanilah aku, tentunya engkau ada berdusta. Engkau hendaklah menjadi kendaraanku, dan kiranya (mau juga) diterakan pada benderaku!" Demikian kata batara Wișṇu, sang Garuḍa memikirkan hal itu tidak akan mau, tetapi takut akan ingkar janji. Akhirnya ia mau, karenanya lalu menjadi kendaraan batara Wiṣnu. Sekarang sang Garuḍa dan batara Wiṣnu sudah bersekutu.

Sang hyang Indra datang menyembah sang Wainateya, sebab senjatanya tidak melukainya. Kata sang Garuḍa (Zoetmulder, 2006:74).

Kutipan di atas, demi janjinya Sang Garuḍa kepada para naga untuk memberikan amrta maka ia bersedia untuk menjadi kendaraan Bhațāra Wiṣnu. Adapun nama lain dari Sang Garuḍa, yaitu Kaśyapi, Wainateya, Suparṇna, Garutmān, Dakșāya, Śālmalin, Tārkṣya, dan Wināyaka. Selain itu, Garuḍa memiliki julukan, antara lain Sitānana berarti 'wajah putih hijau', berarti Rakta-pakșa, 'sayap merah', Śweta-rohita, berarti 'sang putih merah', Suwarṇakāya, berarti 'tubuh emas', Gaganeśwara, berarti 'raja langit',
Khageśwara, berarti 'raja burung', Nāgāntaka, berarti 'pembunuh naga', Pannaganāśana, berarti 'pembunuh naga', Sarpārāti, berarti 'musuh ularular', Taraswin, berarti 'yang cepat', Rasāyana, berarti 'yang bergerak cepat sebagai perak', Kāmachārin, berarti 'yang pergi sesukanya', Kāmāyus, berarti 'yang hidup dengan senang', Chirād, berarti 'makan banyak', Wiṣnuratha, berarti 'kereta Wisnu', Amṛtāharaṇa, berarti 'pencuri amṛta', Sudhāhara, berarti 'pencuri', Surendrajit, berarti 'penakluk Indra', dan Bajrajit, berarti 'penakluk kilat' (http://id.wikipedia.org/ wiki/Garuda, diakses pada 23 Januari 2018 Pukul 09.00 Wita).

Menurut Titib (2003:388-389) cerita mengenai Sang Garuḍa juga terdapat di dalam sastra Hindu yang lain, seperti dalam kekawin Rāmāyana pada cerita Garuḍa membebaskan Rāma dan seluruh pengikutnya dari ikatan naga tali yang dilemparkan oleh Indrajit. Dalam kekawin Bhomāntaka diceritakan Sang Garuḍa membantu Kṛṣna yang bertempur melawan raja raksasa yang bernama Bhoma. Garuḍa dengan kibasan sayapnya menyebabkan mahkota Raja Bhoma terjatuh yang berisikan permata bernama Wijayamāla, permata ini diambil oleh Garuḍa yang menerbangkannya dan Krșna berhasil membunuh Bhoma. Dalam kekawin Bhāratayuddha disebutkan bahwa kereta Kṛṣna dihiasi bendera berwujud raja burung, yaitu Sang Garuḍa seakan-akan berteriak di angkasa diikuti oleh gemuruhnya suara gamelan.

Hindu memiliki kepercayaan terhadap hewan-hewan yang dianggap suci seperti yang dijelaskan oleh kutipan-kutipan teks Ādiparwa di atas, hal ini sesuai dengan sabda Tuhan melalui Kṛ̣ṇa dalam kitab Bhagavadgītā berikut ini.

uccaihśrravasam aśvānām

viddhi mām amritodbhavam,

airāvatài gajendrāṇām

narāṇām ca narādhipam.

(Bhagavadgìtā X.27)

Terjemahannya :

Ketahuilah bahwa diantara bangsa kuda, Aku adalah uccaihsravasa, yang lahir dari amṛta; diantara raja gajah Aku adalah Airavata, diantara manusia biasa Aku adalah maharaja (Pudja, 
1999:263).

$\bar{a} y u d h \bar{a} n \bar{a} m$ aham vajraì

dhenūnām asmi kāmadhuk,

prajanaś cāsmi kandarpah

sarpāṇām asmi vāsukih.

(Bhagavadgītā X.28)

Terjemahannya :

Diantara semua senjata Aku adalah vajra; diantara sapi-sapi Aku adalah kāmadhenu; diantara yang membiakkan keturunan Aku adalah Kandarpa; diantara semua ular, Aku adalah Vāsuki (Pudja, 1999:263).

anantaś cāsmi nāgānām

varuno yādasām aham,

pitrṇām aryamā cāsmi

yamaḥ samiyamatām aham.

(Bhagavadgītā X.29)

Terjemahannya :

Diantara para naga Aku adalah Ananta; diantara penghuni air Aku adalah Varuna; diantara arwah leluhur Aku adalahy Aryamā; diantara penegak hukum Aku adalah Yama (Pudja, 1999:264).

prahlādaś cāsmi daityānāìm

kālah kalayatām aham,

mrgānāàm ca mrgendro 'ham

vainateyaś ca pakșinām.

(Bhagavadgītā X.30)

Terjemahannya :

Diantara para daitya Aku adalah Prahlāda; diantara penghitung Aku adalah waktu; diantara segala binatang Aku adalah singa, diantara segala burung Aku adalah garuda (Pudha, 1999:264).

Sloka Bhagavadgītā di atas, sangat jelas bahwa Hindu juga menganut konsep totemisme. Tuhan diantara bangsa kuda disebut Uccaihśrawa, diantara para gajah Tuhan adalah Airavata, Tuhan juga adalah Kamandhenu diantara para sapi. Diantara para ular Tuhan adalah Bāsuki, Tuhan adalah Ananta diantara para naga. Tuhan adalah singa diantara para binatang dan Tuhan adalah Garuḍa diantara bangsa burung. Penggunaan figur hewan-hewan tertentu untuk mengumpamakan kemahakuasaan Tuhan adalah sebagai sarana yang berfungsi untuk menunjang penanaman sradha.

\section{PENUTUP}

Totemisme adalah suatu keyakinan akan adanya binatang keramat yang sangat dihormati. Di dalam teks Ādiparwa keyakinan tersebut digambarkan melalui Sang Garuda, para naga (Takṣaka, Anantabhoga, dan Bāsuki), dan kūrmarāja. Konsep totemisme dalam Hindu bukan berarti umat Hindu memuja binatang, melainkan umat Hindu menghormati binatang karena binatang merupakan maklhuk ciptaan Sang Hyang Widhi. Adanya totemsime di dalam Hindu dapat memperkaya ajaran teologi Hindu yang sangat kompleks.

\section{DAFTAR PUSTAKA}

Bagus, Lorens.2000. Kamus Filsafat. Jakarta : PT. Gramedia Pustaka Umum.

Cika, I Wayan.2006. Kakawin Sabha Parwa Analisis Filologis. Denpasar : Pustaka Larasan.

Donder, I Ketut.2009. Teologi : Memasuki Gerbang Ilmu Pengetahuan Ilmiah Tentang Tuhan Paradigma Sanatana Dharma. Surabaya : Pāramita.

Pudja, G.1999. Bhagavadgītā. Surabaya : Pāramita.

Suka Yasa, I Wayan.2004. "Brahma Widya dan Nilai Kearifan Lokal Dalam Tattwa Jñāna" (Tesis). Denpasar : Universitas Hindu Indonesia.

Titib, I Made.1996. Veda Sabda Suci Pedoman Praktis Kehidupan. Surabaya : Pāramita.

Titib, I Made.2003. Teologi \& simbol-Simbol dalam Agama Hindu. Surabaya : Pāramita.

Wiana, I Ketut.2009. Air sebagai Ratna Permata Bumi. Naskah lengkap The 3rd SSEASR Confrence. Denpasar, 3-6 juni 2009.

Zoetmulder, P.J.1994. Kalangwan Sastra Jawa 
Kuno Selayang Pandang (Dick Hartoko, Pentj.). Jakarta : Djambatan.

Zoetmulder, P.J.2006. Ādiparva Bahasa Jawa Kuna dan Indonesia. Surabaya : Pāramita. 